\title{
Is It Essential to Consider Respiratory Dynamics?
}

\author{
Youngjoon Kang \\ Department of Emergency Medicine, Jeju National University Hospital, Jeju, Korea
}

Chronic obstructive pulmonary disease (COPD), which is marked by a fixed obstruction of the airway, is a progressive disease including emphysema and chronic bronchitis. According to data from the fourth Korea National Health and Nutrition Survey, the prevalence of COPD is $13.4 \%$ in South Korea [1]. Intensive care unit (ICU) admission is required in more than $25 \%$ of patients with COPD [2]. ICU stays of patients with lung hyperinflation are longer compared to patients without lung hyperinflation [3].

In an acute exacerbation of COPD, airway resistance rises, positive end expiratory pressure (PEEP) rises, and hyperinflation of lungs occurs. Increased lung volume by hyperinflation compresses inferior vena cava and right ventricle, therefore decreases cardiac output and blood pressure. Moreover, asymmetric lung compliance aggravates unilateral lung hyperinflation which is found in unilateral lung transplantation, fibrosis or pneumonia of a single lung [4,5]. Severe obstruction increases work of breathing and fatigue of respiratory muscles [6].

With the understanding about respiratory dynamics, the better strategies will be discussed. The uneven distribution of volume could be reduced by reducing the diameter of the airway [7]. Measurement of lung hyperinflation is integral to the assessment of physiological impairment in individuals with COPD and can effectively be targeted for treatment [8].

Recognition and successful management of the unilateral lung hyperinflation may avoid complications such as barotrauma and hypotension associated with the presence of intrinsic PEEP [9].

\author{
Youngjoon Kang \\ Department of Emergency Medicine, Jeju \\ National University Hospital, 15 Aran 13- \\ gil, Jeju 63241, Korea \\ Tel: +82-64-754-8044 \\ Fax: +82-64-754-8044 \\ E-mail: jedarm@jejunu.ac.kr \\ ORCID \\ Youngjoon Kang \\ http://orcid. org/0000-0002-3550-7755 \\ *No potential conflict of interest relevant to this \\ article was reported.
}

\section{References}

1. Yoo KH, Kim YS, Sheen SS, Park JH, Hwang YI, Kim SH, et al. Prevalence of chronic obstructive pulmonary disease in Korea: the fourth Korean National 
Health and Nutrition Examination Survey, 2008. Respirology 2011;16:659-65.

2. Schmidt M, Demoule A, Deslandes-Boutmy E, Chaize M, de Miranda S, Bèle N, et al. Intensive care unit admission in chronic obstructive pulmonary disease: patient information and the physician's decision-making process. Crit Care 2014;18:R115.

3. Anglès R, Tenorio L, Roman A, Soler J, Rochera M, de Latorre FJ. Lung transplantation for emphysema. Lung hyperinflation: incidence and outcome. Transpl Int 2005;17:810-4.

4. Venuta F, Boehler A, Rendina EA, De Giacomo T, Speich R, Schmid R, et al. Complications in the native lung after single lung transplantation. Eur J Cardiothorac Surg 1999;16:54-8.

5. Eveloff SE, Rounds S, Braman SS. Unilateral lung hyperinflation and herniation as a manifestation of intrinsic PEEP. Chest 1990;98:228-9.

6. An TH. Mechanical ventilation in patients with chronic obstructive pulmonary disease. Korean J Crit Care Med 2003;18:67-73.

7. Yun SH, Lee HJ, Lee YH, Park JC. Evaluation of respiratory dynamics in an asymmetric lung compliance model. Korean J Crit Care Med 2017;32:174181.

8. O'Donnell DE, Webb KA, Neder JA. Lung hyperinflation in COPD: applying physiology to clinical practice. COPD Res Pract 2015;1:4.

9. Kollef MH, Turner JF. Intrinsic PEEP and unilateral lung hyperinflation: pathophysiology and clinical significance. Chest 1992;102:1220-4. 